\title{
A Prospective Randomized Study to Evaluate the Analgesic Efficacy and Quality of Recovery of Perioperative Intravenous Lignocaine Infusion in Laparoscopic Surgeries
}

\author{
Priyabrat Karan' ${ }^{1}$, Nita D'souza², Rajendra Patil ${ }^{3}$
}

\begin{abstract}
Background: The role of intravenous lignocaine perioperatively is studied to evaluate whether it has an opioid-sparing effect, component of a multimodal analgesia regimen, enhancing recovery, and early discharge of the patients undergoing laparoscopic surgery.

Materials and methods: A randomized prospective double-blind study was done on $80 \mathrm{ASA}$ I/II adult patients of both sexes in the age group 18-60 years scheduled for elective laparoscopic surgery under general anesthesia over a period of 6 months. Group L was administered lignocaine $1.5 \mathrm{mg} / \mathrm{kg}$ i.v. bolus followed by and $1.5 \mathrm{mg} / \mathrm{kg} /$ hour i.v. infusion and group NS $10 \mathrm{~mL}$ of $0.9 \%$ normal saline i.v. instead of lignocaine. Results: The intubation response, length of hospital stay, ambulation time, time of the return of bowel movements, use of rescue analgesics, use of opioids, and visual analog scores (VAS) in the saline group were significantly higher as compared to the lignocaine group.

Conclusion: Intravenous lignocaine as bolus and infusion demonstrated a significant decrease in the hemodynamic parameters following intubation and postextubation, provided opioids-sparing role, showed lower VAS scores, fewer rescue analgesics over 24 hours, significantly early bowel movements, ambulation, and discharge.

Keywords: Analgesia, Laparoscopic surgeries, Lignocaine.

Research and Innovation in Anesthesia (2021): 10.5005/jp-journals-10049-0098
\end{abstract}

\section{INTRODUCTION}

Laparoscopic surgeries, being minimally invasive have a major advantage of early ambulation, reduced hospital stay, and better recovery scores. Though the incidence of pain in laparoscopic surgeries is of shorter duration and lower intensity than open surgeries (46-54\%) it needs to be treated effectively. ${ }^{1,2}$ High-quality analgesia is essential to enhance early recovery and discharge. Most often opioid analgesics are considered intra- and postoperatively at varying intervals owing to the multifactorial causes of pain in laparoscopic surgeries in combination with multimodal analgesia. This is attributed to tissue injury (visceral pain), peritoneal irritation largely due to (1) pneumoperitoneum, (2) blood left in the abdomen after surgery, (3) diaphragmatic irritation, (4) also owing to the possible source of pain in laparoscopy from sustained intraoperative pressure on capillary beds in abdominal and possibly retroperitoneal viscera causing nociception. ${ }^{3}$ The adverse effects of opioids (nausea, vomiting, sedation, urinary retention, etc.) limit the benefits and warrant the need for alternative modalities like intraperitoneal instillation of local anesthetic, truncal blocks, wound infiltration, and intravenous drugs such as lignocaine, magnesium, dexamethasone, or ketamine. More recent research has demonstrated that lignocaine decreases pain scores, analgesic consumption, and side effects of opioids but also promotes enhanced recovery after surgery (ERAS). These effects include early ambulation, early feeding (reduced ileus), and patient satisfaction. Lignocaine acts as effective analgesia through its anti-inflammatory effects, anti-hyperalgesic effects, inhibition of nociceptive transmission, and stimulation of inhibitory descending pathways.

Several studies and meta-analyses of these studies have been published and show that perioperative lignocaine infusion is indeed effective but the evidence supporting its use varies as per
${ }^{1}$ Department of Anesthesia and Critical Care, All India Institute of Medical Sciences, Jodhpur, Rajasthan, India

${ }^{2,3}$ Department of Anesthesia, Ruby Hall Clinic, Pune, Maharashtra, India

Corresponding Author: Priyabrat Karan, Department of Anesthesia and Critical Care, All India Institute of Medical Sciences, Jodhpur, Rajasthan, India, Phone: +91 9438478537, e-mail: karanpriyabrat@ gmail.com

How to cite this article: Karan P, D'souza N, Patil R. A Prospective Randomized Study to Evaluate the Analgesic Efficacy and Quality of Recovery of Perioperative Intravenous Lignocaine Infusion in Laparoscopic Surgeries. Res Inno in Anesth 2021;6(2):36-43.

Source of support: Nil

Conflict of interest: None

the surgical procedure. Perioperative i.v. infusion of lignocaine has been used as a method to control postoperative pain. ${ }^{4-7}$

The i.v. use of lignocaine for its anti-hyperalgesic and analgesic properties in the dose of (1.3-3) $\mathrm{mg} / \mathrm{kg} / \mathrm{hour}$ has been used in the past. ${ }^{4,5}$ Most of the studies done in major and minor laparoscopic surgeries have used a dose of $2 \mathrm{mg} / \mathrm{kg}$ i.v. lignocaine and have shown satisfactory results with prolonged infusions of up to 24 hours and had a lower incidence of side effects. Modern postoperative care is focused on multimodal management to enhance recovery. Various drugs including lignocaine, esmolol, alfentanil, and fentanyl have been recommended for the control of hemodynamic events caused by laryngoscopy, tracheal intubation, and subsequent extubation. The usage of multimodal analgesia, reduced opioid consumption, resuming early oral intake, promoting early ambulation, and better patient experience would help to achieve ERAS. Lignocaine as an intravenous bolus dose 
has been used for minimizing hemodynamic changes associated with intubation and extubation. ${ }^{8,9}$ Furthermore, i.v. infusion has been used for postoperative analgesia. We investigated whether i.v. perioperative lignocaine (bolus and infusion) would be able to provide adequate analgesia in addition to obtunding pressor response and improving the quality of recovery in laparoscopic surgeries. ${ }^{10-13}$ We chose a lower dose of $1.5 \mathrm{mg} / \mathrm{kg}$ of i.v. lignocaine bolus and $1.5 \mathrm{mg} / \mathrm{kg} /$ hour of infusion for a limited duration after surgery to assess whether it would be as effective and thereby to assess the role of i.v. lignocaine as an analgesic and whether it enhances postoperative recovery and is a suitable alternative to sparing use of opioids.

\section{Materials and Methods}

After approval of our institutional ethics committee, a randomized prospective double-blind study was done on 80 ASA physical status 1 and 2 adult patients of both sexes in the age group 18-60 years scheduled for elective laparoscopic surgery under general anesthesia. The data were collected in a pretested proforma after obtaining written informed consent from the patient for the study. The primary objective was to evaluate the analgesic efficacy of intraoperative lignocaine-infused patients, the effectiveness of lignocaine infusion on the pressor response at intubation and extubation, and the effect of intravenous lignocaine on postoperative analgesia. The secondary objectives included observing any side effects of intravenous lidocaine infusions, the role of i.v. lignocaine on return of bowel movements postoperatively and its effect on the time to discharge from the hospital. The study population of 80 patients was randomly allocated into two groups based on a computerized randomization table, with 40 patients in each group.

The two groups (1) Group L-Lignocaine $1.5 \mathrm{mg} / \mathrm{kg}$ i.v. bolus diluted to $10 \mathrm{~mL}$ with normal saline and $1.5 \mathrm{mg} / \mathrm{kg} / \mathrm{hour}$ i.v. infusion was continued till 15 minutes postoperatively prepared in a $20-\mathrm{mL}$ syringe. (2) Group NS $-10 \mathrm{~mL}$ of $0.9 \%$ normal saline i.v. bolus and infusion of normal saline at a similar volume infusion rate as it would be with $1.5 \mathrm{mg} / \mathrm{kg} /$ hour of lignocaine till 15 minutes postoperatively prepared in a $20-\mathrm{mL}$ syringe. To facilitate blinding the initial drug either lignocaine $1.5 \mathrm{mg} / \mathrm{kg}$ or saline was given as a $10-\mathrm{mL}$ volume. The person administering the drug and the evaluator were different.

\section{Inclusion Criteria}

The inclusion criteria considered was as follows:

Age 18-60 years, males or females, ASA 1 or 2, elective laparoscopic surgeries, duration of surgery of 2 hours, elective laparoscopic surgeries, BMI 18-26.

\section{Exclusion Criteria}

Patient refusal, pregnant females, and known allergy to study drugs were excluded from the study.

\section{Statistical Methods}

Software PS: power and sample size calculation software was used. Descriptive statistical analysis was carried out in the study to explore the distributions of several characteristics of the cases studied. Results on categorical data were shown as $n$ (\% of cases) and the data on continuous measurements were presented on mean \pm standard deviation OR median (minimum-maximum). The statistical significance of the difference of various categorical variables across two groups was tested using the Chi-square test. Inter-group statistical significance was assessed of difference of various continuous measurements, independent sample $t$-test was used after confirming the underlying normality assumption. The $p$ values $<0.05$ were considered to be statistically significant. All the hypotheses were formulated using two-tailed alternatives against each null hypothesis. The entire data were statistically analyzed using Statistical Package for Social Sciences (SPSS version 16.0, Inc., Chicago, USA) for MS Windows.

\section{Conduct of Anesthesia}

After 3 minutes of preoxygenation with $6 \mathrm{~L}$ /minute, lignocaine i.v. $1.5 \mathrm{mg} / \mathrm{kg}$ bolus was administered in group $\mathrm{L}$ and saline likewise in group NS. General anesthesia was administered using inj. propofol $2 \mathrm{mg} / \mathrm{kg}$, inj. fentanyl $2 \mu \mathrm{g} / \mathrm{kg}$, and inj. rocuronium 0.9 $\mathrm{mg} / \mathrm{kg}$. Orotracheal intubation was performed and lungs were ventilated with nitrous oxide, oxygen, and inhalational agent and MAC maintained at 0.8-1.2. After induction, inj. dexamethasone $0.1 \mathrm{mg} / \mathrm{kg}$ i.v. was administered and infusions were started as per randomization intraoperatively till 15 minutes postoperatively. Intraoperatively inj. paracetamol $1 \mathrm{~g}$ i.v. and anti-emetic ondansetron $0.1 \mathrm{mg} / \mathrm{kg}$ i.v. were administered. To ensure the same infusion rate in both groups (e.g., $1.5 \mathrm{mg} / \mathrm{kg} /$ hour for $60 \mathrm{~kg}$ person comes to be $90 \mathrm{mg}$ ). So in group L $200 \mathrm{mg}$ of lignocaine was diluted till 20 $\mathrm{mL}$ with normal saline and was started at $9 \mathrm{~mL} / \mathrm{hour}$ and in group NS saline infusion was also started at $9 \mathrm{~mL} /$ hour as per lignocaine group calculation. Intraoperative tachycardia and hypertension if $>20 \%$ of baseline warranted a check of MAC, relaxation, and if adequate inj. fentanyl $0.25 \mu \mathrm{g} / \mathrm{kg}$ i.v. as titrated bolus was given to all patients to manage the intraoperative pain. Port sites were locally infiltrated with $0.2 \%$ ropivacaine with a volume of $5 \mathrm{~mL}$ per port site. At the end of the surgery, neuromuscular block was antagonized in all patients with neostigmine $0.05 \mathrm{mg} / \mathrm{kg}$ and glycopyrrolate $0.01 \mathrm{mg} / \mathrm{kg}$ and was extubated in the operating room. All patients were observed in the recovery room and visual analog score (VAS), number of rescue analgesics, duration of hospital stay, amount of opioid used, duration of ileus, and postoperative nausea and vomiting (PONV) was assessed and noted at $0,2,4,6,12,18$, and 24 hours. Rescue analgesics required by the patient according to the VAS $(\geq 3)$ were assessed after completion of surgery. Our first rescue analgesic was inj. diclofenac $75 \mathrm{mg}$ slow i.v. bolus in case of VAS $(\geq 3)$ and second rescue analgesic was given if there was no relief beyond 30 minutes of first analgesic rescue, i.e., inj. tramadol $50 \mathrm{mg}$ i.v. Several postoperatively adverse effects of lignocaine like dizziness, drowsiness, tinnitus, blurred or double vision, vomiting and sensation of heat, cold, numbness; twitching, tremors, and convulsions were noted. Duration of ileus was assessed by checking the first return of bowel movement by noting the time of passing flatus since the surgery was completed. Ambulatory time was measured as the time interval between postoperative periods to the start of ambulation of the patient. The duration of hospital stay was also noted in both groups (Fig. 1).

\section{Results}

The two groups were comparable with regards to demographics: age, sex, BMI, duration of surgery, various surgeries in each group (Tables 1 and 2). The intubation response in the saline group was significantly higher as compared to the lignocaine group. The hemodynamic parameters after extubation in the lignocaine group were significantly lower than the saline group, though not in the DBP after extubation (Table 3). The use of additional fentanyl in the lignocaine group was significantly less as compared to the saline group with a $p$ value of 0.002 (Table 4). The average dose of 


\begin{tabular}{|c|c|c|c|}
\hline $\begin{array}{l}\text { Induction } \\
1.5 \mathrm{mg} / \mathrm{kg} \\
\text { lignocaine at } \\
\text { the time of } \\
\text { induction of } \\
\text { anesthesia }\end{array}$ & $\begin{array}{l}\text { Maintenance } \\
1.5 \mathrm{mg} / \mathrm{kg} / \mathrm{hour} \\
\text { lignocaine infusion } \\
\text { continued in L group } \\
\text { and Inj fentanyl } \\
0.25 \mu \mathrm{g} / \mathrm{kg} \text { used if } \\
\text { tachycardia }+ \\
\text { hypertension }>20 \% \\
\text { of baseline after a } \\
\text { check of MAC, } \\
\text { relaxation adequacy }\end{array}$ & $\begin{array}{l}\text { PACU } \\
\text { Lignocaine infusion } \\
1.5 \text { mg/kg/hour } \\
\text { continued } 15 \text { minutes } \\
\text { postoperative VAS } \\
\text { monitored over } 24 \text { hours } \\
\text { and rescue analgesics } \\
\text { administered as per } \\
\text { VAS =/>3. First rescue: } \\
\text { Inj diclofenac } 75 \text { mg i.v. } \\
\text { Second rescue } \\
\text { Inj tramadol } 50 \text { mg i.v. }\end{array}$ & $\begin{array}{l}\text { Postoperative } \\
\text { monitoring } \\
\text { VAS, adverse } \\
\text { effects, flatus, } \\
\text { ambulation, } \\
\text { discharge days }\end{array}$ \\
\hline
\end{tabular}

Fig. 1: Outline of the study procedure

Table 1: Age, sex, and BMI demographic characteristics of patients in two groups

\begin{tabular}{llll}
\hline Characteristics & Group L & Group NS & p value \\
\hline Number of patients & 40 & 40 & \\
Age (in years) Mean \pm S.D. & $40.3 \pm 12.01$ & $41.7 \pm 7.83$ & 0.462 \\
$\quad$ Range & 42 & 30 & \\
BMI & $22.05 \pm 1.10$ & $22.15 \pm 1.16$ & 0.838 \\
$\quad$ Range & 4 & 5 & \\
Sex & & & \\
$\quad$ Number of males & $22(55.0 \%)$ & $19(47.5 \%)$ & 0.502 \\
$\quad$ Number of females & $18(45.0 \%)$ & $21(52.5 \%)$ & \\
Surgery duration (minute) & 107.1 & 105.5 & 0.757 \\
\hline
\end{tabular}

Table 2: Types of surgeries in two groups

\begin{tabular}{lrrrll}
\hline Surgery & \multicolumn{1}{c}{ L } & NS & All & p value & Statistical significance \\
\hline Diagnostic laparoscopy (Lap) & 3 & 1 & 4 & 0.286 & NS \\
Lap appendix & 13 & 12 & 25 & & \\
Lap cholecystectomy & 14 & 14 & 28 & \\
Lap cystectomy & 3 & 4 & 8 & \\
Lap inguinal hernia & 3 & 5 & 3 & \\
Lap myomectomy & 1 & 2 & 5 & \\
Lap umbilical hernia & 3 & 2 & 80 & \\
All & 40 & 40 & & \\
\hline
\end{tabular}

Table 3: Vitals noted in both the groups before intubation (BI), after intubation (Al), and after extubation (AE)

\begin{tabular}{|c|c|c|c|c|}
\hline Variables & Group L & Group NS & $p$ value & Statistical significance \\
\hline \multicolumn{5}{|c|}{ Vitals after intubation (BI) in both the groups } \\
\hline $\mathrm{HR}(\mathrm{BI})$ & $72.22 \pm 4.08$ & $73.40 \pm 5.35$ & 0.273 & NS \\
\hline $\mathrm{SBP}(\mathrm{BI})$ & $125.55 \pm 5.18$ & $123.5 \pm 10.83$ & 0.5 & NS \\
\hline $\mathrm{DBP}(\mathrm{BI})$ & $73.03 \pm 6.56$ & $75.55 \pm 8.22$ & 0.133 & NS \\
\hline MAP (BI) & $88.22 \pm 5.39$ & $91.25 \pm 7.88$ & 0.52 & NS \\
\hline \multicolumn{5}{|c|}{ Vitals after intubation (AI) in both the groups } \\
\hline $\mathrm{HR}(\mathrm{Al})$ & $82.33 \pm 9.75$ & $87.63 \pm 6.84$ & 0.043 & $\mathrm{~S}$ \\
\hline $\mathrm{SBP}(\mathrm{Al})$ & $124.23 \pm 12.36$ & $142.25 \pm 9.81$ & 0.0001 & $\mathrm{~S}$ \\
\hline $\mathrm{DBP}(\mathrm{Al})$ & $82.25 \pm 11.48$ & $79.80 \pm 6.11$ & 0.239 & NS \\
\hline MAP (Al) & $95.39 \pm 10.48$ & $100.22 \pm 5.22$ & 0.0001 & $\mathrm{~S}$ \\
\hline \multicolumn{5}{|c|}{ Vitals after extubation (AE) in both the groups } \\
\hline $\mathrm{HR}(\mathrm{AE})$ & $88.53 \pm 6.92$ & $98.30 \pm 7.09$ & 0.0001 & $\mathrm{~S}$ \\
\hline $\mathrm{SBP}(\mathrm{AE})$ & $124.40 \pm 8.52$ & $149.58 \pm 8.1$ & 0.0001 & $\mathrm{~S}$ \\
\hline $\mathrm{DBP}(\mathrm{AE})$ & $82.38 \pm 7.04$ & $84.05 \pm 4.82$ & 0.218 & NS \\
\hline MAP (AE) & $95.53 \pm 5.66$ & $105.55 \pm 4.29$ & 0.0001 & $\mathrm{~S}$ \\
\hline
\end{tabular}

$\mathrm{HR}$, heart rate; SBP, systolic blood pressure; $\mathrm{DBP}$, diastolic blood pressure; MAP, mean arterial pressure 
To Evaluate the Analgesic Efficacy and Quality of Recovery of Perioperative Intravenous Lignocaine Infusion

Table 4: Distribution of EXFENT used in patients between two groups

\begin{tabular}{|c|c|c|c|}
\hline \multirow[b]{2}{*}{ EXFENT } & \multicolumn{2}{|c|}{ Group } & \multirow[b]{2}{*}{$p$ value } \\
\hline & $L$ & NS & \\
\hline Used & 12 & 37 & 0.002 \\
\hline Not used & 28 & 3 & \\
\hline Total & 40 & 40 & \\
\hline
\end{tabular}

Table 5: Comparison of VAS between both groups at $0,2,4$, and 6 hours

\begin{tabular}{|c|c|c|c|c|}
\hline & \multicolumn{2}{|c|}{ Group } & \multirow[b]{2}{*}{$p$ value } & \multirow[b]{2}{*}{ Statistical } \\
\hline & $L(\%)$ & NS (\%) & & \\
\hline \multicolumn{5}{|c|}{ VAS 0 hours } \\
\hline 0 & $6(15.0)$ & $0(0.0)$ & 0.0001 & $S$ \\
\hline 1 & $16(40.0)$ & $0(0.0)$ & & \\
\hline 2 & $4(10.0)$ & $2(5.0)$ & & \\
\hline 3 & $14(35.0)$ & $12(30.0)$ & & \\
\hline 4 & $0(0.0)$ & $21(52.5)$ & & \\
\hline 5 & $0(0.0)$ & $5(12.5)$ & & \\
\hline Total & $40(100.0)$ & $40(100.0)$ & & \\
\hline \multicolumn{5}{|c|}{ VAS 2 hours } \\
\hline 0 & $13(33.3)$ & $10(25.0)$ & 0.009 & $S$ \\
\hline 1 & $11(25.6)$ & $1(2.5)$ & & \\
\hline 2 & $8(20.5)$ & $13(32.5)$ & & \\
\hline 3 & $8(20.5)$ & $16(40.0)$ & & \\
\hline Total & 40 (100) & $40(100.0)$ & & \\
\hline \multicolumn{5}{|c|}{ VAS 4 hours } \\
\hline 0 & $17(43.6)$ & $22(55.0)$ & 0.068 & NS \\
\hline 1 & $13(33.3)$ & $13(32.5)$ & & \\
\hline 2 & $7(15.4)$ & $0(0.0)$ & & \\
\hline 3 & $3(7.7)$ & $5(12.5)$ & & \\
\hline Total & $40(100)$ & $40(100.0)$ & & \\
\hline \multicolumn{5}{|c|}{ VAS 6 hours } \\
\hline 0 & $29(72.5)$ & $24(60.0)$ & 0.046 & $S$ \\
\hline 1 & 7 (17.5) & $16(40)$ & & \\
\hline 2 & $1(2.5)$ & $0(0.0)$ & & \\
\hline 3 & $3(7.5)$ & $0(0.0)$ & & \\
\hline Total & $40(100.0)$ & $40(100.0)$ & & \\
\hline
\end{tabular}

additional fentanyl used was $15.83 \mu \mathrm{g}$ in the lignocaine group vs $33.37 \mu \mathrm{g}$ in the saline group which was almost double as compared with the lignocaine group.

Visual analog scores were significantly lower in the lignocaine group at 0,2 , and 6 hours though at 4 hours was not statistically significant. At 0 hours, $65 \%$ of patients in the lignocaine group had a VAS $<3$ which was significant whereas $95 \%$ of patients in the saline group had a VAS of $>2$. Likewise, at 2 hours, $79.5 \%$ of patients in the lignocaine group had a VAS $<3$ which was significant whereas $60 \%$ of patients in the saline group had a VAS of $<3$ (Table 5). Inadequate pain relief (VAS $\geq 3$ ) in both the groups warranted a rescue analgesia. The number of patients requiring diclofenac in the lignocaine group (67.5\%) as the first rescue was significantly less as compared to the saline group (95\%) $(p=0.002)$. Likewise, the use of tramadol as a second rescue was significantly higher in the NS group as compared to the lignocaine group. Thirty-five percent of patients needed tramadol in group L vs $72.5 \%$ in NS group $(p=0.001)$. Bowel movements in the saline group $(568.0 \pm 44.09$ minutes) were significantly delayed as compared to the lignocaine group $(434.0 \pm 42.71$ minutes $)(p=0.0001)$. Ambulation time in the lignocaine group was significantly earlier than the saline group, i.e., 14.5 hours in the lignocaine group as compared to 16.2 hours in the saline group ( $p=0.003)$. Thus, the length of hospital stay was significantly longer in the saline group which was 1.83 days as compared with the lignocaine group which was 1.62 days ( $p=$ 0.0001).

\section{Discussion}

The increasing use of laparoscopy for major and minor surgeries has made it essential to provide efficient pain control, a better quality of recovery, early ambulation, and limit the hospital stay. Usage of intravenous lignocaine in acute pain came from its established role in chronic pain. Lignocaine interrupts neuronal transmission by blocking sodium channels in nervous tissue. Animal studies have suggested that the systemic effect of lignocaine is mainly by preventing depolarization of the neuronal membrane which is prior damaged or dysfunctional. Systemic lignocaine prevents the proliferation of new active sodium channels in traumatized or scarred tissue, thereby blocking their firing..$^{14}$ Lignocaine has analgesic, anti-hyperalgesic, and anti-inflammatory properties. It is proposed to reduce central sensitization and decrease $N$-methyl-Daspartate receptor-mediated post-synaptic depolarization. Studies have also shown a significant decrease in systemic inflammatory markers. ${ }^{1,5,15}$

\section{Hemodynamics}

Wilson way back in 1991 concluded through their study that 1.5 $\mathrm{mg} / \mathrm{kg}$ i.v. lignocaine 4 minutes before intubation completely obtunded the pressor response but not the chronotropic response to intubation. ${ }^{16}$ Kindler and colleagues stated that lignocaine in combination with esmolol attenuated the heart rate and pressor response vs only heart rate by esmolol though may be accompanied by hypotension. ${ }^{17}$ Intravenous injection of lignocaine in a dose $1 \mathrm{mg} / \mathrm{kg}, 2$ minutes before tracheal extubation prevented both coughing and increase in arterial pressures and heart rate during and after extubation as studied by Bidwai et al. ${ }^{18}$ The decrease in the heart rate, SBP, and DBP (blunting of the sympathoadrenal response) with i.v. lignocaine has been substantial when in combination with opioids as noted in various studies ${ }^{16,19,20}$

In our study, a significant decrease in laryngoscopic response to heart rate and mean arterial pressure were observed in group $L$ as compared to group NS during intubation. A decrease in HR (82.33 $\pm 9.75)$ in group $L$ as compared to $H R(87.63 \pm 6.84)$ in group NS was found during intubation with a $p$ value of 0.043 (Table 3). Jain and Khan observed similar results in patients undergoing elective laparoscopic cholecystectomy at $1.5 \mathrm{mg} / \mathrm{kg}$ i.v. bolus administered and thereafter an infusion at a rate of $1.5 \mathrm{mg} / \mathrm{kg} / \mathrm{hour}{ }^{8}$ They found that in the lignocaine group there was a change in heart rate postintubation $(105.13 \pm 13.49)$ and postextubation $(109.83 \pm$ $12.83)$ which was significantly lower than respective heart rates with postintubation (115.57 \pm 13.44$)$ and postextubation (118.17 \pm 17.19$)$ with the saline group with a $p$ value $<0.005$. Murthy and Kumar studied laparoscopic surgeries with a dose of $1.5 \mathrm{mg} / \mathrm{kg}$ lignocaine i.v. bolus followed by an infusion dose of $1.5 \mathrm{mg} / \mathrm{kg} / \mathrm{hour}$ till 1 hour postoperatively. ${ }^{9}$ They too found a significantly lower heart rate in the lignocaine group after intubation and postextubation with a $p$ value of $<0.001$. Whereas no changes in DBP were noted in both the groups at intubation and postextubation. Hence, according to our observation, intravenous lignocaine was effective in reducing the pressor response, specifically the SBP and MAP. 
Various studies have noted lignocaine on controlling hemodynamic changes have shown similar results periintubation and periextubation. ${ }^{8,9,21}$ Other studies have reported a significant effect on either PR ${ }^{17,22}$ or MAP alone. ${ }^{16,23}$ In contrast to it, few other studies have also noted no significant attenuating effect of lignocaine on the hemodynamic parameters..$^{24,25}$ Such phenomena can be attributed to the action of lignocaine in causing arteriolar vasodilatation, ${ }^{26}$ downregulating the autonomic reaction, ${ }^{21}$ having cough suppressant activity, ${ }^{22,27}$ and increasing the depth of general anesthesia. $^{28}$

\section{Intraoperative Use of Opioids}

In our study, we have observed that the use of i.v. bolus and i.v. infusion of lignocaine has shown an opioid-sparing role and enhanced recovery. We observed reductions in pain scores. Thirty percent of patients in group $L$ required fentanyl intraoperatively as compared to $92.5 \%$ of patients in group NS ( $p$ value $=0.002$ ) (Table 4). The NS group needed double the dose (15.83 vs $33.37 \mu \mathrm{g}$ ) which was needed in group L. McKay et al. found that there was a $30 \%$ reduction of the amount of opioid use in patients undergoing ambulatory surgeries which were significant and comparable to our study and suggest an opioid-sparing role of lignocaine. ${ }^{29}$ Ventham et al. in their meta-analysis noted lowered 24-hour opioids consumption, lower pain scores at 2, 12, and 24 hours with i.v. lignocaine following laparoscopic surgery and was similar to our study. ${ }^{30}$ Patients undergoing laparoscopic bariatric surgeries required significantly lower morphine $(10 \mathrm{mg})$ requirement and this facilitated better quality of recovery scores in the lignocaine group (1.5 mg/kg i.v. bolus and $2 \mathrm{mg} / \mathrm{kg} /$ hour i.v. infusion). ${ }^{11}$ Intravenous lignocaine attenuated the postoperative pain and decreased the morphine consumption after abdominal surgery due to prevention of central hyperalgesia and likewise reduced opioid requirement very significantly in laparoscopic cholecystectomy vs intraperitoneal lignocaine. ${ }^{1,31}$ In our study, in both the groups, the port sites were infiltrated postoperatively, though intraperitoneal instillation was not practiced.

\section{Dose and Duration of Infusion}

Perioperative lignocaine in a dose ranging from 0.5 to $1.5 \mathrm{mg} / \mathrm{kg}$ bolus followed by 1.5 to $3 \mathrm{mg} / \mathrm{kg} /$ hour has over the years shown to have reduced pain (noted as lower VAS pain scores) in various open and laparoscopic abdominal surgeries. ${ }^{6,32-35}$ Lignocaine infusions of $2 \mathrm{mg} / \mathrm{kg} / \mathrm{hour}$ reduced pain and the requirement of opioids over the first 24 hours. Longer duration of infusions provided a proportionate reduction in opioids use but showed no benefit of continuing infusions beyond 24 hours. ${ }^{33}$ Overall requirement of analgesics was lowered by $35 \%$ when lignocaine infusions were continued up to 1-hour post-surgery, whereas further reduced up to $83 \%$ when infusions were run for 24 hours. ${ }^{35}$ The duration of the analgesic action of i.v. lignocaine varied between 2 hours and 48 hours postoperatively, ${ }_{1}^{15,27,36}$ whereas one study also reported no immediate effect but analgesic action seen on day 2 and 3 postoperatively. ${ }^{1}$ Its effects were seen after i.v. lignocaine is most effective when the infusion is administered intraoperatively and this effect may persist for days to weeks beyond the infusion time and the plasma halflife thus suggesting that other mechanisms (prevention of the hypersensitivity of the central or peripheral nervous system or both) do exist apart from voltage-gated sodium channels. 1,37,38 The type of surgery may be liable to explain the difference in observations. Previous studies have shown that lignocaine has best effect when administered during the presence of a significant nociceptive input. ${ }^{11,12}$

\section{VAS}

Reduction in pain was significantly lower in group $L$ at 0,2 , and 6 hours and further reduction was seen at 12 and 24 hours as compared with the NS group in our study. Differing analgesic efficacy of lignocaine would be noted in the context of different surgical procedures. It has shown most effectiveness after major open surgeries after prolonged infusions owing to its antiinflammatory effects. ${ }^{5}$ Intravenous lignocaine has similar beneficial effects on the outcome as epidural anesthesia after laparoscopic cholecystectomy, thus highlighting its analgesic role which significantly reduced opioid consumption, postoperative pain, and fatigue scores. ${ }^{5}$

A decrease in VAS, fentanyl consumption, proportionate reduction in the shoulder tip pain without any adverse effect in i.v. lignocaine groups in laparoscopic cholecystectomy and appendicectomy ${ }^{13,39}$ Studies have shown analgesic efficacy of lignocaine relates to the afferent (sensory) innervation of the manipulated tissues. Intravenous lignocaine has the potential to improve postoperative analgesia following abdominal surgical procedures associated with visceral pain or postoperative ileus. Analgesic efficacy was not observed in laparoscopic fundoplication as it was surgical manipulation of a diaphragm which has more somatic sensory innervation via the phrenic nerve. ${ }^{40}$

\section{Rescue Analgesics}

In our study, we found that $67.5 \%$ of patients in group $L$ needed first rescue analgesia as compared to group NS whereas $95 \%$ of patients required first rescue analgesic ( $p$ value $=0.002$ ). The time of the first request for additional analgesia in the lignocaine group was longer than saline group ( $9.56 \pm 2.06$ vs $1.82 \pm 0.9$ hours) in spinal surgery using a bolus dose of $2 \mathrm{mg} / \mathrm{kg}$ before induction followed by $3 \mathrm{mg} / \mathrm{kg} /$ hour infusion till the end of surgery. ${ }^{41}$ Our study also showed similar results but with a low dose of lignocaine used, was observed to have lower pain scores at $0,2,4,6,12$, and 24 hours as compared to saline and significantly lower at 0, 2, and 6 hours. We observed a significant difference in the number of patients requiring second rescue analgesics in group $L$ and group NS.

Reviewing literature there have been inconsistent reports of the analgesic benefits of intravenous lignocaine. Benefits have been noted in colorectal, abdominal, complex spine surgeries, ischemic pain, post-amputation pain, breast surgery ${ }^{32,42-47}$ additionally for postoperative pain relief. ${ }^{1,27}$ Some studies including hip arthroplasty and open abdominal hysterectomy have not shown a statistically significant reduction in pain. ${ }^{48,49}$

Therefore, although opioid analgesics play an important part in pain management their use may be associated with an increase in postoperative complications which delays discharge of the patient. Consequently, as in our study, lignocaine was noted to be a suitable non-opioid alternative which appears to be a part of multimodal pain relief regimen especially when we encounter instances of patient refusal or contraindication of epidural or regional techniques. ${ }^{50}$

\section{Bowel Function/lleus}

Reduction in nausea and vomiting, early resumption of oral intake, and early ambulation are guided by the early return of bowel function. Opioids have a higher predisposition to nausea and vomiting though our study did not show a difference in the PONV 
To Evaluate the Analgesic Efficacy and Quality of Recovery of Perioperative Intravenous Lignocaine Infusion

score. The ability of lignocaine to shorten the duration of ileus is attributed to a direct excitatory effect on intestinal smooth muscle which may be a consequence of the blockade of inhibitory reflexes originating from the myenteric plexus. ${ }^{51}$ Postoperative ileus is consequent to active abdominal reflexes that are maintained in any inflammatory response. ${ }^{52}$ Duration of ileus is not related to the duration of that particular surgery. Peritoneal surgery mediates the release of prostaglandins, kinins, and histamine, all of which further activate afferent nerve fibers. ${ }^{51}$ Amide local anesthetics are potent anti-inflammatory drugs (inhibiting migration of granulocytes and release of lysosomal enzymes) with prolonged duration of action after the serum levels have decreased. ${ }^{51}$ Amide anesthetics given to attenuate postoperative ileus need not be administered epidurally to be beneficial. ${ }^{15}$ Lignocaine-treated patients (bolus and infusion up to 1-hour post-op) experienced flatulence in a significantly shorter time, were more comfortable, and with a shorter hospital stay after radical prostate surgery with no adverse effects of the infusion. ${ }^{15}$ Perioperative lignocaine infusion shortens the duration of post-op ileus by 8 hours ${ }^{6,35}$ and reduces PONV by $10-20 \%$., ${ }^{6,34}$ In our study, the mean time for the return of bowel movement in group L was early $(434 \pm 42.71)$ minutes/7.2 hours as compared with group NS $(568 \pm 44.09)$ minutes/9.4 hours $(p<0.05)$. Marret et al. noted that the duration of postoperative ileus was decreased in cases by 8.36 hours as compared to controls with a $p<0.001$ which concurs with our study. ${ }^{6}$ Contrastingly in a meta-analysis done by Ventham et al. did not observe a significantly earlier return of bowel movement in both cases and controls possibly due to a variety of different surgeries. ${ }^{30}$ We took the passing of flatus as an indicator of the return of bowel function whereas their study noted the time as until resumption of diet which again was dependent on the type of surgeries the patients have undergone and possibly surgical team protocol. This may be due to the heterogeneity in the type of surgery. ${ }^{30}$ Significant reduction in time to return of normal diet, reduced ileus and hospital stay may be considered as a cost-effective strategy though we have not computed the same. This meta-analysis observed diet resumption was quicker in six studies but no differences in time until first bowel movement (seven studies) or time until flatus (eight studies) that could be attributable to major and minor laparoscopic surgeries in the meta-analysis. ${ }^{30}$ Koppert et al. concluded that perioperative lignocaine (starting 30 minutes before 1-hour post-op infusion) resulted in the early return of bowel function, less overall pain, and thus shorter hospital course though not significant.

\section{Ambulation}

In our study, we found the mean ambulatory time in group $L$ was $(14.5 \pm 2.86)$ hours as compared to group NS $(16.2 \pm 1.96)$ hours ( $p$ value $=0.003$ ). Lauwick et al. studied the functional walking capacity in laparoscopic surgeries with a bolus dose of $1.5 \mathrm{mg} / \mathrm{kg}$ i.v. lignocaine and fentanyl $1.5 \mu \mathrm{g} / \mathrm{kg}$ i.v. bolus followed by $2 \mathrm{mg} /$ $\mathrm{kg} /$ hour infusion in comparison with inj. fentanyl $3 \mu \mathrm{g} / \mathrm{kg}$ i.v. bolus. ${ }^{7}$ They found that the 2-minute walk test significantly decreased by an average of $60 \%$ in both groups on a postoperative day 1 , but patients in the lignocaine group ambulated 26 minutes earlier ( $p$ $=0.009$ ) which concurs with our study. This highlights an opioidsparing early ambulation. Our study also showed similar results in terms of earlier ambulation but with a lower dose of infusion of 1.5 $\mathrm{mg} / \mathrm{kg} / \mathrm{hour}$ as compared with the above study. This may suggest that an infusion of $<2 \mathrm{mg} / \mathrm{kg} / \mathrm{hour}$ would be sufficient to facilitate ambulation as an endpoint of effective postoperative analgesia. Though we have encouraged early ambulation in both groups, it has been as per the patient comfort and we have not noted time duration or a walk test for the same.

\section{Discharge}

Our study noted the mean time of discharge in group $L$ as $(39.05 \pm$ $5.69)$ hours as compared with group NS (44.45 \pm 2.81$)$ hours with a $p$ value (0.0001). A meta-analysis noted a shorter length of stay of 5.40 hours in the i.v. lignocaine group like in our study. ${ }^{6}$ Similarly, studies have recorded a reduction in hospital stay ranging from 26 minutes to 20 hours in abdominal surgeries and laparoscopic bariatric cases $(p=0.03)$, respectively. ${ }^{6,11}$ After a bolus dose and continuous infusion of $2 \mathrm{mg} / \mathrm{kg} / \mathrm{hour}$ for 4 hours postoperative, Herroeder et al. noted a significant acceleration of bowel function and a decreased hospital stay by 24 hours. ${ }^{4}$ We have observed similar results by a lower dose of i.v. lignocaine bolus and infusion for a period of 15 minutes after surgery. Length of hospital stay was shorter in the lignocaine group ( $3.15 \pm 1.08$ days) as compared to the control group ( $4.55 \pm 1.31$ days $)$ in patients undergoing spine surgery $(p=0.001) .{ }^{41}$ The mean length of hospital stay as noted in various laparoscopic surgeries was shorter in the lignocaine group but was not significant. ${ }^{30,40}$ The difference in the above studies from our study with regards to mean length of hospital stay may be due to heterogeneity in types of surgeries in their study, attributes to multiple local factors, culture and practices followed. ${ }^{30,40}$ The metaanalysis by Ventham et al. in laparoscopic surgeries recently showed no difference in length of hospital stay ( 9 studies, 453 participants) though noted a significantly reduced incidence of nausea and vomiting (12 studies, 647 participants). ${ }^{30} \mathrm{~A}$ low-dose lignocaine infusion started before induction and continued for 15 minutes postoperatively can have an impressive effect on pain, bowel function, and hospital stay. ${ }^{15}$ Various studies and reviews inferred perioperative i.v. lignocaine reduced postoperative analgesia, aided opioids-sparing role, reduced intraoperative anesthetic requirement (less inhalational agents), resulted in an earlier return of bowel function, obtunded production of interleukins for up to 72 hours, and reduced hospital stay. ${ }^{35,42}$ Shorter hospital stay after retropubic radical prostatectomy have shown benefits in significant cost-savings up to $32 \%$ per patient. ${ }^{53}$

\section{Side Effects of Lignocaine Infusion}

Toxicity resulting from perioperative i.v. lidocaine infusion such as neurologic changes (confusion, euphoria, tinnitus, lightheadedness), dizziness and visual disturbances (blurring of vision), ${ }^{29}$ and cardiac dysrhythmias $^{42}$ is exceedingly rare. . $^{34,35}$ Ventham et al. noted one cardiac side effect in the i.v. lignocaine group amongst 742 patients studied in the meta-analysis. ${ }^{30}$ Lidocaine plasma levels of approximately $2 \mathrm{mg} / \mathrm{mL}$ were noted after bolus and infusions of the dose we used in our study with no related side effects except for sedation or excessive drowsiness for an hour in some studies. ${ }^{1,8,54}$ Intravenous lignocaine can blunt sympathetic responses to tracheal extubation which may cause delayed awakening as patients are less responsive to the endotracheal tube. ${ }^{55}$ Various studies with an infusion rate varying between 1.5 and $3 \mathrm{mg} / \mathrm{kg} / \mathrm{hour}$ for $6-24$ hours postoperatively reported plasma lignocaine levels varying from 1 to $3.8 \mathrm{mg} / \mathrm{mL}^{1,15,36,56}$ which were well below toxic levels $(5 \mathrm{pg} / \mathrm{mL}){ }^{57}$ Signs of toxicity occurs at a plasma concentration of $>5 \mu \mathrm{g} / \mathrm{mL}$ which was not achieved even when i.v. lignocaine was given continuously for over 14 days in case of severe migraine. ${ }^{58}$ Some studies have limited infusions to a duration of 180 minutes to avoid the possibility of toxicity in case serum levels are not monitored. ${ }^{8}$ Our study showed no such side effects. The dual advantage we observed of 
using lignocaine was, firstly reducing opioid requirement during surgery and secondly limiting the immediate postoperative side effects of opioids. Our study in addition also underlines the safety of lignocaine infusions used perioperatively.

\section{Conclusion}

Multimodal analgesia is the norm currently practiced and has been evolving since the emergence of literature on the sparing use of opioids. Limitations of the running infusions in the wards concerning safety prompted us to study the effects of short-duration infusions on overall patient recovery after laparoscopic surgeries. Our study showed i.v. lignocaine $1.5 \mathrm{mg} / \mathrm{kg}$ infusion plays an important role in lowering the pain scores, reducing the requirement of rescue analgesics with no side effects, and enhanced recovery in terms of early bowel movements, ambulation, and shorter hospital stay. Perioperative benefits of i.v. lignocaine as a preemptive analgesia is a suitable option to the multimodal analgesia regimen, especially when there are limitations in the usage of regional anesthesia (contraindications, refusal, or failures) or opioids. In conclusion, intravenous lignocaine $1.5 \mathrm{mg} / \mathrm{kg}$ i.v. bolus followed by $1.5 \mathrm{mg} /$ $\mathrm{kg} / \mathrm{hour}$ infusion demonstrated a significant decrease in the hemodynamic parameters following intubation and postextubation, provided opioids-sparing role, showed lower VAS, fewer rescue analgesics over 24 hours, significantly early bowel movements, earlier ambulation, and discharge. Shorter PACU stays and long-term effects of shorter duration of varying dosages of lidocaine infusions need study to evaluate its usefulness in the patient recovery.

\section{Limitations of OUR Study}

Larger sample size and inclusion of major gastrointestinal surgeries would be beneficial in understanding the role of lignocaine better. The hospital stay is likely to have skewed distribution and be affected by local factors, culture and practice. The results of this study cannot be extrapolated to other settings such as orthopedic surgery or major open abdominal surgeries. The requirement of an inhalational agent or total cost savings perioperatively was not studied. Blood serum levels were not studied though at similar doses the literature review documented safe blood levels. The duration of our study is limited to 24 hours, whereas beyond this time duration the effect is yet to be ascertained.

\section{Acknowledgment}

To Dr Subhashree Samantaray from AlIMS Jodhpur for helping with the editing of the article.

\section{References}

1. Koppert W, Weigand M, Neumann F, et al. Perioperative intravenous lidocaine has preventive effects on postoperative pain and morphine consumption after major abdominal surgery. Anesth Analg 2004;98(4):1050. DOI: 10.1213/01.ane.0000104582.71710.ee.

2. Ekstein P, Szold A, Sagie B, et al. Laparoscopic surgery may be associated with severe pain and high analgesia requirements in the immediate postoperative period. Ann Surg 2006;243(1):41-46. DOI: 10.1097/01.sla.0000193806.81428.6f.

3. Choi JB, Kang K, Song MK, et al. Pain characteristics after total laparoscopic hysterectomy. Int J Med Sci 2016;13(8):562-568. DOI: 10.7150/ijms.15875.

4. Herroeder S, Pecher S, Schönherr ME, et al. Systemic lidocaine shortens length of hospital stay after colorectal surgery. Ann Surg 2007;246(2):192-200. DOI: 10.1097/SLA.0b013e31805dac11.

5. Kaba A, Laurent SR, Detroz BJ, et al. Intravenous lidocaine infusion facilitates acute rehabilitation after laparoscopic colectomy.
Anaesthesia 2007;106(1):11-18. DOI: 10.1097/00000542-20070100000007.

6. Marret E, Rolin M, Beaussier M, et al. Meta-analysis of intravenous lidocaine and postoperative recovery after abdominal surgery. Br J Surg 2008;95(11):1331-1338. DOI: 10.1002/bjs.6375.

7. Lauwick S, Kim DJ, Michelagnoli G, et al. Intraoperative infusion of lidocaine reduces postoperative fentanyl requirements in patients undergoing laparoscopic cholecystectomy. Can J Anaesth 2008;55(11):754. DOI: 10.1007/BF03016348.

8. Jain S, Khan RM. Effect of peri-operative intravenous infusion of lignocaine on haemodynamic responses to intubation, extubation and post-operative analgesia. Indian J Anaesth 2015;59(6):342-347. DOI: 10.4103/0019-5049.158733.

9. Murthy TKK, Kumar PVV. Effect of perioperative intravenous lignocaine infusion on haemodynamic responses and postoperative analgesia in laparoscopic cholecystectomy surgeries. Anesth Pain Med 2018;8(2):e63490.

10. Kang H, Kim B-G. Intravenous lidocaine for effective pain relief after inguinal herniorrhaphy: a prospective, randomized, double-blind, placebo-controlled study. J Int Med Res 2011;39(2):435-445. DOI: 10.1177/147323001103900211.

11. De Oliveira GS, Duncan K, Fitzgerald P, et al. Systemic lidocaine to improve quality of recovery after laparoscopic bariatric surgery: a randomized double-blinded placebo-controlled trial. Obes Surg 2014;24(2):212-218. DOI: 10.1007/s11695-013-1077-x.

12. Ram D, Sistla SC, Karthikeyan VS, et al. Comparison of intravenous and intraperitoneal lignocaine for pain relief following laparoscopic cholecystectomy: a double-blind, randomized, clinical trial. Surg Endosc 2014;28(4):1291-1297. DOI: 10.1007/s00464-013-3325-5.

13. Yang SY, Kang H, Choi GJ, et al. Efficacy of intraperitoneal and intravenous lidocaine on pain relief after laparoscopic cholecystectomy. J Int Med Res 2014;42(2):307-319. DOI: $10.1177 / 0300060513505493$.

14. Eipe N, Gupta S, Penning J. Intravenous lidocaine for acute pain: an evidence-based clinical update. BJA Education 2016;16(9):292-298. DOI: 10.1093/bjaed/mkw008.

15. Groudine SB, Fisher HAG, Kaufman RP, et al. Intravenous lidocaine speeds the return of bowel function, decreases postoperative pain, and shortens hospital stay in patients undergoing radical retropubic prostatectomy. Anesth Analg 1998;86(2):235-239. DOI: 10.1213/00000539-199802000-00003.

16. Wilson IG, Meiklejohn BH, Smith G. Intravenous lignocaine and sympathoadrenal responses to laryngoscopy and intubation. The effect of varying time of injection. Anaesthesia 1991;46(3):177-180. DOI: 10.1111/j.1365-2044.1991.tb09403.x.

17. Kindler $\mathrm{CH}$, Schumacher PG, Schneider MC, et al. Effects of intravenous lidocaine and/or esmolol on hemodynamic responses to laryngoscopy and intubation: a double-blind, controlled clinical trial. J Clin Anesth 1996;8(6):491-496. DOI: 10.1016/0952-8180(96)00109-2.

18. Bidwai AV, Bidwai VA, Rodgers $C R$, et al. Blood pressure and pulse rate responses to endotracheal extubation with and without prior injection of lidocaine. Anesthesiology 1979;51(2):171-173. DOI: 10.1097/00000542-197908000-00020.

19. Lev R, Rosen P. Prophylactic lidocaine use preintubation: a review. J Emerg Med 1994;12(4):499-506. DOI: 10.1016/0736-4679(94)90347-6.

20. Malde AD, Sarode V. Attenuation of the hemodynamic response to endotracheal intubation: fentanyl vs lignocaine. Int J Anaesth 2007;12:1.

21. Reiz S, Mangano DT, Bennett S. Intravenous lignocaine to reduce the circulatory stress response to laryngoscopy and intubation in addition to other adjuncts such as opioids, vasodilators, $\beta$ blockers and laryngeal nerve blocks. In: Nimmo WS, Rowbotham DJ, Smith $\mathrm{G}$, ed. Anesthesia and cardiac disease. 2nd ed., London: Blackwell Scientific Publication; 1994. pp. 1212-1263.

22. Drenger B, Pe'er J. Attenuation of ocular and systemic responses to tracheal intubation by intravenous lignocaine. Br J Ophthalmol 1987;71(7):546-548. DOI: 10.1136/bjo.71.7.546.

23. El-Sayed W, Hasanein R. Intraoperative lidocaine infusion attenuates tourniquet induced hypertension in patients undergoing anterior 
cruciate ligament reconstruction under general anesthesia. Egypt $J$ Anaesthe 2016;32(3):345-350. DOI: 10.1016/j.egja.2015.12.006.

24. Feng CK, Chan KH, Liu KN, et al. A comparison of lidocaine, fentanyl, and esmolol for attenuation of cardiovascular response to laryngoscopy and tracheal intubation. Acta Anaesthesiolog Sinica 1996;34(2):61-67.

25. Lin PL, Wang YP, Chou YM, et al. Lack of intravenous lidocaine effects on HRV changes of tracheal intubation during induction of general anesthesia. Acta Anaesthesiolog Sinica 2001;39(2):77-82.

26. Stoelting RK, Hillier SC. Pharmacology and physiology in anesthetic practice. Lippincott Williams \& Wilkins; 2012.

27. Wu CT, Borel CO, Lee MS, et al. The interaction effect of perioperative cotreatment with dextromethorphan and intravenous lidocaine on pain relief and recovery of bowel function after laparoscopic cholecystectomy. Anesth Analge 2005;100(2):448-453. DOI: 10.1213/01.ANE.0000142551.92340.CC.

28. Hamill JF, Bedford RF, Weaver DC, et al. Lidocaine before endotracheal intubation: Intravenous or laryngotracheal? Anesthesiology 1981;55(5):578-581. DOI: 10.1097/00000542-198111000-00016.

29. McKay A, Gottschalk A, Ploppa A, et al. Systemic lidocaine decreased the perioperative opioid analgesic requirements but failed to reduce discharge time after ambulatory surgery. Anesthe Analge 2009;109(6):1805-1808. DOI: 10.1213/ANE.0b013e3181be371b.

30. Ventham NT, Kennedy ED, Brady RR, et al. Efficacy of intravenous lidocaine for postoperative analgesia following laparoscopic surgery: a meta-analysis. World J Surg 2015;39(9):2220-2234. DOI: 10.1007/ s00268-015-3105-6.

31. Perniola A, Fant F, Magnuson A, et al. Postoperative pain after abdominal hysterectomy: a randomized, double-blind, controlled trial comparing continuous infusion vs patient-controlled intraperitoneal injection of local anaesthetic. $\mathrm{Br} J$ Anaesth 2014;112(2):328-336. DOI: 10.1093/bja/aet345.

32. Sun Y, Li T, Wang N, et al. Perioperative systemic lidocaine for postoperative analgesia and recovery after abdominal surgery: a meta-analysis of randomized controlled trials. Dis Colon Rectum 2012;55(11):1183-1194. DOI: 10.1097/DCR.0b013e318259bcd8.

33. Kranke $\mathrm{P}$, Jokinen J, Pace $\mathrm{NL}$, et al. Continuous intravenous perioperative lidocaine infusion for postoperative pain and recovery. Cochrane Database Syst Rev 2015;7(7):CD009642. DOI: 10.1002/14651858.CD009642.pub2.

34. Vigneault L, Turgeon AF, Côté $D$, et al. Perioperative intravenous lidocaine infusion for postoperative pain control: a meta-analysis of randomized controlled trials. Can J Anaesth 2011;58(1):22-37. DOI: 10.1007/s12630-010-9407-0.

35. Mc Carthy GC, Megalla SA, Habib AS. Impact of intravenous lidocaine infusion on postoperative analgesia and recovery from surgery: a systematic review of randomized controlled trials. Drugs 2010;70(9):1149-1163. DOI: 10.2165/10898560-000000000-00000.

36. Cassuto J, Wallin G, Hogstrom S, et al. Inhibition of postoperative pain by continuous low-dose intravenous infusion of lidocaine. Anesth Analg 1985;64(10):971-974.DOI: 10.1213/00000539-198510000-00005.

37. Mc Cleane G. Intravenous lidocaine: an outdated or underutilized treatment for pain. J Palliat Med 2007;10(3):798-805. DOI: 10.1089/ jpm.2006.0209.

38. Amir R, Argoff CE, Bennett GJ, et al. - The role of sodium channels in chronic inflammatory and neuropathic pain. J Pain 2006;7(5Suppl3):S1-S29. DOI: 10.1016/j.jpain.2006.01.444.

39. Kim TH, Kang H, Hong JH, et al. Intraperitoneal and intravenous lidocaine for effective pain relief after laparoscopic appendectomy: a prospective, randomized, double-blind, placebo-controlled study. Surg Endosc 2011;25(10):3183-3190. DOI: 10.1007/s00464-011-1684-3.

40. Dale GJ, Phillips S, Falk GL. The analgesic efficacy of intravenous lidocaine infusion after laparoscopic fundoplication: a prospective, randomized, double-blind, placebo-controlled trial. Local Reg Anesth 2016;9:87-93. DOI: 10.2147/LRA.S119483.
41. Ibrahim A, Aly M, Farrag W. Effect of intravenous lidocaine infusion on long-term postoperative pain after spinal fusion surgery. Medicine (Baltimore) 2018;97(13):e0229. DOI: 10.1097/MD.0000000000010229.

42. Kuo CP, Jao SW, Chen KM, et al. Comparison of the effects of thoracic epidural analgesia and i.v. infusion with lidocaine on cytokine response, postoperative pain and bowel function in patientsundergoing colonic surgery. Br JAnaesth 2006;97(5):640646. DOI: 10.1093/bja/ael217.

43. Wongyingsinn M, Baldini G, Charlebois P, et al. Intravenous lidocaine versus thoracic epidural analgesia: a randomized controlled trial in patients undergoing laparoscopic colorectal surgery using an enhanced recovery program. Reg Anesth Pain Med 2011;36(3):241248. DOI: 10.1097/AAP.0b013e31820d4362.

44. Farag E, Ghobrial M, Sessler DI, et al. Effect of perioperative intravenous lidocaine administration on pain, opioid consumption, and quality of life after complex spine surgery. Anesthesiology 2013;119(4):932-940. DOI: 10.1097/ALN.0b013e318297d4a5.

45. Frölich MA, McKeown JL, Worrell MJ, et al. Intravenous lidocaine reduces ischemic pain in healthy volunteers. Reg Anesth Pain Med 2010;35(3):249-254. DOI: 10.1097/AAP.0b013e3181d23386.

46. Wu CL, Tella P, Staats PS, et al. Analgesic effects of intravenous lidocaine and morphine on post amputation pain: a randomized doubleblind, active placebo-controlled, crossover trial. Anesthesiology 2002;96(4):841-848. DOI: 10.1097/00000542-20020400000010.

47. Grigoras A, Lee $P$, Sattar F, et al. Perioperative intravenous lidocaine decreases the incidence of persistent pain after breast surgery. Clin J Pain 2012;28(7):567-572. DOI: 10.1097/AJP.0b013e31823b9cc8.

48. Martin F, Cherif K, Gentili ME, et al. Lack of impact of intravenous lidocaine on analgesia, functional recovery, and nociceptive pain threshold after total hip arthroplasty. Anesthesiology 2008;109(1):118-123. DOI: 10.1097/ALN.0b013e31817b5a9b.

49. Bryson GL, Charapov I, Krolczyk G, et al. Intravenous lidocaine does not reduce length of hospital stay following abdominal hysterectomy. Can J Anaesth 2010;57(8):759-766. DOI: 10.1007/s12630-010-9332-2.

50. de Oliveira CM, Issy AM, Sakata RK. Intraoperative intravenous lidocaine. Rev Bras Anestesiol 2010;60(3):325-333. DOI: 10.1016/ S0034-7094(10)70041-6.

51. Rimback G, Cassuto J, Tollesson PO. Treatment of postoperative paralytic ileus by intravenous lidocaine infusion. Anesth Analg 1990;70(Supplement):414-419. DOI: 10.1213/00000539-19900200100414.

52. Rimback G, Cassuto J, Wallin G, et al. Inhibition of peritonitis by amide local anesthetics. Anesthesiology 1988;69(6):881-886. DOI: 10.1097/00000542-198812000-00013.

53. Licht MR, Klein EA. Early hospital discharge after radical retropubic prostatectomy: impact on cost and complication rate. Urology 1994;44(5):700-704. DOI: 10.1016/s0090-4295(94)80211-4.

54. Lee JH, Koo BN, Jeong JJ, et al. Differential effects of lidocaine and remifentanil on response to the tracheal tube during emergence from general anaesthesia. Br J Anaesth 2011;106(3):410-415. DOI: 10.1093/ bja/aeq396.

55. Wallin G, Cassuto J, Högström S, et al. Effects of lidocaine infusion on the sympathetic response to abdominal surgery. Anesth Analg 1987;66(10):1008-1013. DOI: 10.1213/00000539-198710000-00017.

56. Birch K, Jorgensen J, Chraemmer-Jorgensen B, et al. Effect of i.v. lignocaine on pain and the endocrine metabolic responses after surgery. Br J Anaesth 1987;59(6):721-724. DOI: 10.1093/bja/59.6.721.

57. Stoelting RK. Cardiac antidysrhythmic drugs. In: Stoelting RK, ed. Pharmacology and physiology in anesthetic practice. Philadelphia: JB Lippincott; 1987. pp. 327-328.

58. Williams DR, Stark RJ. Intravenous lignocaine infusion for the treatment of chronic daily headache with substantial medication overuse. Cephalalgia 2003;23(10):963-971. DOI: 10.1046/j.14682982.2003.00623.x 